\title{
MODERN APPROACH TO PROJECT MANAGEMENT, USAGE, AND SUCCESS RATE OFAGILE METHODOLOGIES: AN EVIDENCE FROM SERBIA
}

\author{
Miloš Vučeković*, \\ Goran Avlijaš
}

Singidunum University, Belgrade, Serbia

\begin{abstract}
:
The global trend of using "Agile" tools and techniques within organizations and implementing them on everyday projects is evident in the past decade, especially in the information technology and software engineering industries, where constant change of requirements and directions are quite common and mostly appreciated. Prior research showcased that the success rates of projects implementing "Agile" are generally higher and that the damage done from canceled or failed engagements are far less then on traditionally run projects. Many of the authors suggested that more value has been provided to the customers by using iterative approach and by utilizing "scrum" multidisciplinary teams, which also include team members from the client side. The main purpose of this paper is to showcase the adoption level of modern project management methodologies and their perceived importance in Serbia, by conducting research among its users, managers, and IT experts from the country. This paper contributes to the topic by providing real industry insights and opinions by professionals using modern project management tools and techniques in their workplace.
\end{abstract}

Keywords:

Agile Adoption; Project Management, Agile transformations.

\section{INTRODUCTION}

In the last two decades, the practice of project management has evolved to the new heights, changing the way companies and organizations plan and execute projects. Ever since the creation of Agile manifesto in 2001. [1], the benefits of more flexible and incremental approach to project management and project delivery were obvious. Today, almost twenty years after the formal inception of "Agile Manifesto" document, many organizations have already implemented a big subset of agile methodologies and tools on their projects and programs, empowering their employees and customers to achieve greater value and satisfaction on both ends. As previous research has shown, this trend is also helping many organizations in becoming more productive and efficient, especially when working on high demanding endeavors or overly complex programs [2].

\section{Correspondence:}

Miloš Vučeković

e-mail:

milos.vucekovic.11@singimail.rs 
Project management is mostly defined as the application of knowledge, skills, tools and techniques to project activities to meet the project requirements [3], but it has evolved in recent years and now includes other activities or shares similarities with other fields, creating a wider bound by sharing and using methodologies with recurring nature of the process management [4]. Recent research shows that number of projects included in bigger corporate strategies is constantly increasing, composing multi-project efforts divided only by deliverables and grouped in big "programs" or in some cases "portfolios", which makes them extremely complex and hard to manage, even with the usage of "Big Data" tools and techniques [5]. Given this fact, it should be clear that the main goal of modern project management is development and delivery of value to the clients in a proactive way that improves guidelines of the PMBOK and the "Cruise-control" paradigm [6].

The "Agile Manifesto" adheres to previously mentioned goals of modern project management by providing simple values drawn by the leading industry experts of that time and adjusting them for the current industry needs and requirements.

Because of this premise, the starting point of this research was to find previously published scientific papers on the topic of adoption levels and success rates of Agile project management methodologies and then compare their results and findings with our research in the case of Serbia. The main hypothesis from authors of this paper was that the adoption level of modern project management methodologies and techniques in Serbia are on pair with other countries, with similar usage and success rates.

\section{LITERATURE REVIEW}

Many surveys have been conducted in previous years on the topic of project success and usage of modern methodologies and techniques on projects in multiple industries. One of the most quoted research was performed by Standish Group, an internationally acclaimed IT research and consulting company, which created the infamous "Chaos Report" in 1994 and showcased the troubling state that the IT project management industry was in. Stating that only $16 \%$ of the projects involved in the study was successful, they created a staggering amount of $189 \%$ software cost overruns [7]. The report also presented a new methodology for establishing the standard for measuring project success by defining terms such as on time, on budget and on target as the primary attributes. In the years that followed, The Standish group continued to monitor and report on the state of the project management in the IT industry, publishing several new "Chaos Reports", and one of the latest reports of this kind has been adopted as a standard for the future research on this topic. The 2015 "Chaos Report" included a new set of attributes for measuring project success including on time, on budget, on target, on goal, value, and satisfaction as the primary attributes [8]. Their report included results for FY2011-FY2015, based on the data from more than 10.000 software projects and showed that only $36 \%$ of the projects were successful in the year 2015, $45 \%$ of them were challenged and $19 \%$ failed. On average for those years, only $44 \%$ of the project were on budged, $40 \%$ on time and $56 \%$ on target. Also, using the new methodology attributes and adding the $59 \%$ of the projects were valuable, $62 \%$ on goal and $56 \%$ satisfactory.

\begin{tabular}{lccccc}
\cline { 2 - 6 } & 2011 & 2012 & 2013 & 2014 & 2015 \\
\hline SUCCESSFUL & $29 \%$ & $27 \%$ & $31 \%$ & $28 \%$ & $29 \%$ \\
\hline CHALLENGED & $49 \%$ & $56 \%$ & $50 \%$ & $55 \%$ & $52 \%$ \\
\hline FAILED & $22 \%$ & $17 \%$ & $19 \%$ & $17 \%$ & $19 \%$ \\
\hline
\end{tabular}

Table 1. Modern resolution for all project (On time, on budget and satisfactory result) Source: (Standish Group International, 2015)

The Standing Group "Chaos Report” also noted that project size is a single most important factor for the outcome of the project, reporting that only $6 \%$ of the "Grand" projects are being successful and, on the opposite, the $61 \%$ of "Small" ones are being successful [8]. In addition, many recent studies identified similar attributes contributing to project failure, including bad requirement engineering as one of the primary causes [9].

In the similar manner, one important research suggested that the Agile methodologies are widely used in the project management and that the project success is related to the extent this modern approach is being used [10]. Furthermore, one of the most interesting finding of this research is the fact that there was no correlation between "seasoned" staff and project success, showing that Agile is a powerful tool even for inexperienced teams [10]. Also, the most recurring theme in the surveys conducted on this topic was that the Agile methodologies contribute to innovation, flexibility and value orientation of the traditional business more than ever before, giving them comparable advantage over the organizations that are not yet implementing this methodology on 
their projects [11]. Combining these approaches, by using modern software applications and project management tools, it has never been easier to plan and execute projects and then measure the success rate and progress within organizations [12].

Furthermore, many studies in this field tried to define the critical success factors for agile projects but with different results and conclusions. For example, one study showed that "correct delivery strategy", "proper practice of agile software engineering techniques" and "high-caliber team" could only be called critical [13], and the other showed no relation between them and success, only to confirm that "strong executive support" and "project type" had no influence either, as described in previous research [14]. The second study performed by D. Stankovic (2013) was conducted in the similar region as the research presented in this document and represents the early attempts to quantify usage of modern project management tools and techniques and their success rate in the SEE region [14].

In addition, there are studies showcasing the implementations of "Agile" paradigm in digital transformation projects done in Finland, highlighting productivity, quality, and responsiveness as main motivators for their endeavors [2]. This concludes that for most of the research conducted on this topic, the Standish Group findings and reports are the baseline for comparisons and metrics with other data gathered from different sources.

\section{PROJECT MANAGEMENT METHODOLOGIES}

Modern project management methodologies compound of many different ideas, techniques and tools bound together for the same purpose of tackling obstacles that emerged in the last three decades. Many renowned institutions presented their solutions and frameworks, including the Project Management Institute with the PMBOK guide and the United Kingdom Government with the PRINCE 2 method. At the same time, many experts from the IT industry became heavily involved in complex software development projects which failed in large numbers [8], creating the large gap between the traditional pre-planned project management paradigm and the IT industry specific problem of constant scope change and technology debt. Because of this, many embraced the more simplified model of project management, based on feature request from the users, quality requirements and technology advancement.
That ensured the emergence of popular methods such as SCRUM and Extreme Programing in the mid 90's, even before the "Agile" manifesto was created. Therefore, for the purpose of this document, some of the most popular frameworks and methods were used in our questionnaire, including PMBOK, PRINCE 2, SCRUM, XP, KANBAN and AGILE for the group category.

\section{METHODOLOGY AND RESEARCH SAMPLE}

Using the survey methodology [25], author conducted a research on the application of project management methodologies and their success rate in the year 2019. The online survey was conducted in Serbia within the IT professional's community and engaged 53 participants who were selected based on subjective sampling, students, freelancers and full-time employees that had contact with or worked on projects in last five years (98.1\%) were included. Among the survey participants, 96.23\% confirmed that they permanently live in Serbia, and only $3.77 \%$ answered that they live elsewhere. Most of the respondents are employed full time (64.15\%), but the rising trend in freelance and part time employment among younger working population is evident, declaring their status in our survey by $15.09 \%$ and $11.32 \%$ respectfully. The rest of our participants replied either that they are students (5.66\%) or unemployed (3.77\%).

Majority of the respondents are professional workers in areas of software engineering (30.19\%), project management (22.64\%) and consultancy (18.87\%), while others $(20.75 \%)$ choose different occupations not mentioned in the survey. Only the small number of the respondents selected "product owner" $(7.55 \%)$ as their occupation, showing that most of the project work is done for other clients, organizations, or governments.

\section{FINDINGS AND DISCUSSION}

Within the conducted survey 8 questions were presented to the participants, of which some were the control questions with the scope to determine the demographics of the participants. The results presented in this document are directly corelated to the research topic of usage of the modern project management methodologies in Serbia and their success rate. In the survey, the following questions were asked:

- Do you reside in the Republic of Serbia?

- Are you employed?

- Are you working in any of the following positions?

- Have you been part of a project in the last 5 years? 
- Do your projects use any of the following methodologies?

- What is the success rate of the projects you worked on?

- Do you think that agile techniques and methodologies have helped you to increase success, raise product quality and customer satisfaction?

- On what kind of projects did you mostly work?

As indicated by the participants, modern project management methods and techniques are immensely popular in Serbia, choosing Agile and Scrum (47.2\%), Kanban (28.3\%) and XP (15.1\%) respectfully. Furthermore, one third of our respondents choose Waterfall (32.1\%) traditional approach and only small number of participants responded that they use complex methodologies on their projects, PMBOK (9.4\%) and PRINCE2(5.7\%) (Fig 1.).

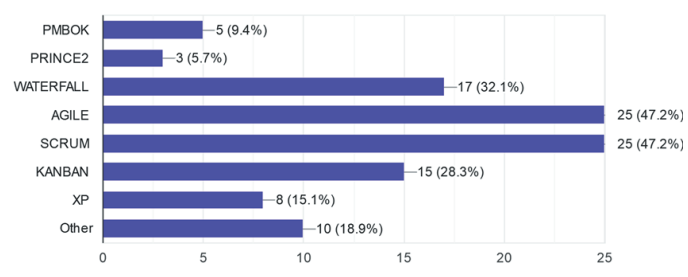

Fig 1. Survey responses on using methodologies and techniques on their projects (Source: Author)

The responders of this survey mostly selected IT related fields by answering that they work on the Web Application development (32.08\%), Business software development (26.42\%), Information Systems implementations (20.75\%), Game Development (9.43\%) and on other projects (11.32\%) (Fig 2).

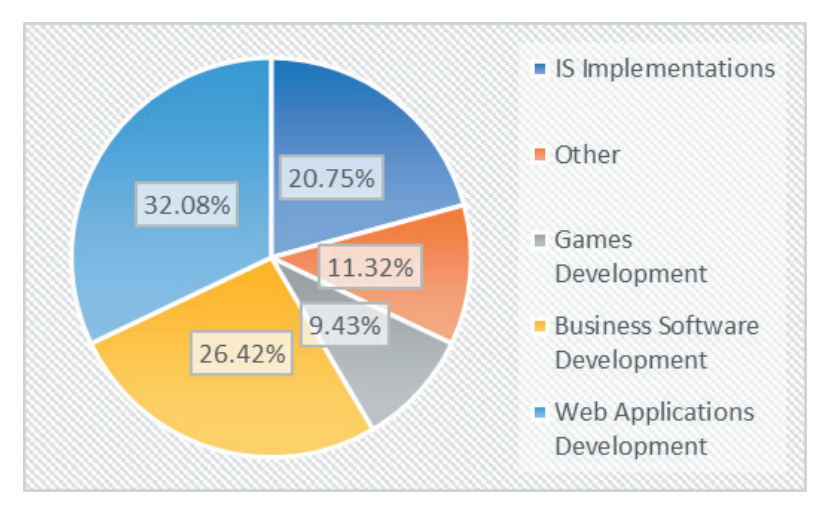

Fig 2. The project types where the survey responders were involved in (Source: Author)
The survey participants were asked about the success rate of the projects that they participated on. Majority of them $(58.10 \%)$ and $(35.20 \%)$ responded with $100 \%$ and $75 \%$ success rate respectively, with only small portion of them $(6.70 \%)$ responded that their projects have $50 \%$ success rate (Fig 3.).

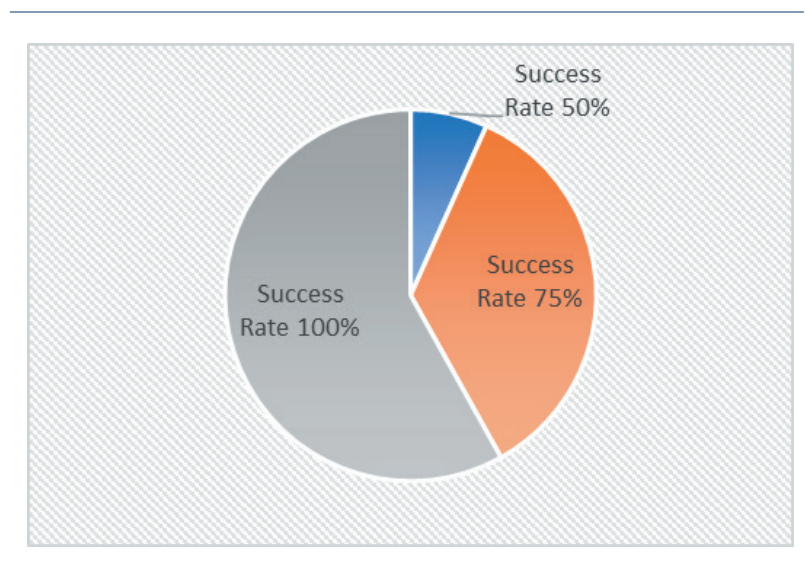

Fig 3. The project success rates (Source: Author)

This is aligned with the worldwide trends in project management [9], and also very similar with the results of the latest revised version of the "Chaos Report", showing improvement and higher success rates from the previous report presented in the 90s, and with new attributes taken into account, defining success by "on budget", "on time" and "on target" [8]. As mentioned before, this paper uses "Chaos" reports from Standish group as a baseline for comparisons and analysis.

Most of the participants in this survey (80.39\%) agree that agile techniques and methodologies helped them reach higher success rates, better quality, and client satisfaction and only a small number of the participants (19.61\%) disagree with that statement (Fig 4.). This result continues to show improvement in usage of modern project management tools and techniques, and it is a clear indicator of the value it brings into the industry. Other studies show successful implementation on larger scale and on enterprise levels, including using Agile methodologies in digital transformation of large organizations [2]. 


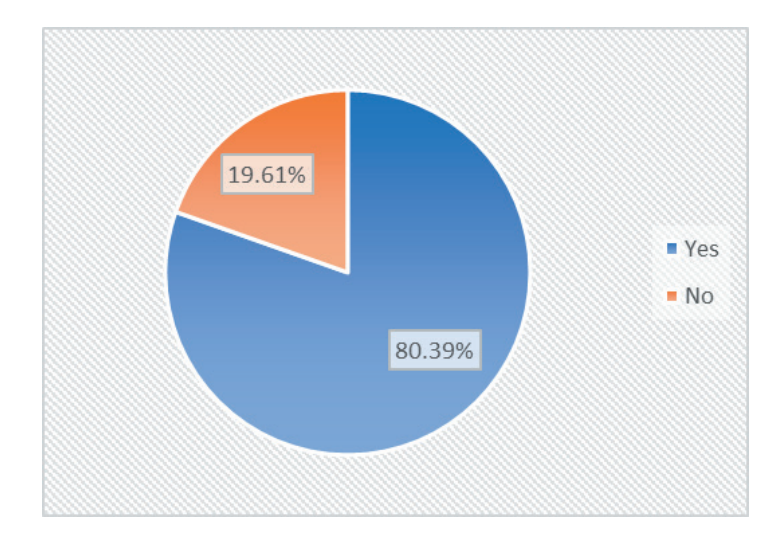

Fig 4. Do Agile tools and techniques help achieve higher success rates, quality, and customer satisfaction?

(Source: Author)

Furthermore, the "Annual State of Agile Report" $14^{\text {th }}$ edition, with over 40,000 survey participants responding during the previous years and conducted among many executives, practitioner and consultants, showcased similar trends mentioned in this paper, finding that the most used agile framework is Scrum (75\%) in general, and SAFE for SCRUM at scale (35\%) [26]. Also, the report highlighted organization culture as the biggest challenge with resistance to change, inadequate management support and sponsorship ranked at odds with Agile values. [26]

\section{CONCLUSION}

From the more traditional approach to project management by sequentially creating, planning, and executing tasks, to more iterative and agile way of doing things, the practice has greatly evolved in the past thirty years, changing the way people organize their work, create requirements, plan budgets and prioritize tasks. Many companies have started employing proven "Agile" methods and tools within their organizations, transforming company cultures, business processes, and operational models. Previous studies have shown that the primary goals for most business organizations are to be more resilient, lower production costs, and reduce project failure rates to a minimum. Furthermore, by comparing previously published reports from Standish Group and VersionOne / Digital.ai, it is evident that there is big progress in all previously mentioned areas, especially in the software development and information technology industries. The main hypothesis of this paper was based on those results, and with the premise from the authors that the adoption level, usage, and success rate of modern project management methodologies in
Serbia are on the same or similar levels to those showcased in the previous reports. The authors have shown that there is a solid basis for such hypothesis by showcasing the survey research data and by comparing the results with similar studies done on the same topic. With over half of the respondents selecting some type of "modern" project management methodology, authors concluded that the global trend of "Agile" is also well established in Serbia, especially among professionals in IT and other tech industries. Methods such as "Scrum", "Kanban" and "XP" are well represented in the sampling data with "Agile" as a main group selected by the survey respondents. Furthermore, the second biggest group of the survey respondents selected more traditional and standardized approaches to project management by employing "Waterfall", "PMBOK" and "PRINCE2" on their projects, showcasing that there is still space for robust and highly detailed frameworks. The authors also concluded that most of the survey respondents are using some form of standardized or well-known project management methodology or technique, with only a small percent of them not using any special method, tool, or technique on their projects. Most of the survey participants acknowledged that "Agile" helped them become more successful, with over two-thirds of them reporting remarkably high project success rates.

This research presents new insights into project management trends in Serbia, based on the responses and opinions of the survey participants included in the study. Furthermore, this paper contributes to the topic by uncovering the value and impact of using Agile methodologies on digital transformation and software development projects, thus explaining its high popularity among engineering and project management professionals. As shown in this paper, there is still significant work do be done in regard to successful project delivery with a still relatively high percentage of failed or partially delivered projects.

In this paper and with the conducted research, the authors agree that the survey data is a preliminary one and that future research is needed to better understand the correlation between adoption levels, usage of modern project management methodologies, digital maturity, and highly specialized teams on project success rates. Furthermore, there is space and need for deeper insights and scientifically proven evidence for the hypothesis proposed by this research.

Finally, further research will continue to provide insights on project management evolution as a whole and the popularity of modern approaches to 21 st-century challenges. 


\section{REFERENCES}

[1] K. Beck, M. Beedle, A. Van Bennekum, A. Cockburn, W. Cunningham, M. Fowler, J. Grenning, J. Highsmith, A. Hunt and R. Jeffries, "Manifesto for agile software development.," 2001.

[2] P. Kettunen, M. Laanti, F. Fagerholm, T. Mikkonen and T. Mannisto, "Finnish enterprise agile transformations: a survey study," International Conference on Agile Software Development, pp. 97--104, 2019.

[3] Project Management Institute, A guide to the project management body of knowledge (PMBOK guide), 2013.

[4] W. Chmielarz and M. Zborowski, "Determinants of using project management in the implementation of information systems," Procedia Computer Science, vol. 126, no. 1, pp. 1224-1236., 2018.

[5] J. Whyte, A. Stasis and C. Lindkvist, "Managing change in the delivery of complex projects: Configuration management, asset information and 'big data," International Journal of Project Management, 34(2), vol. 34, no. 2, pp. 339-351, 2016.

[6] P. Morris, "Reconstructing project management reprised: A knowledge perspective," Project Management Journal, vol. 44, no. 5, pp. 6-23, 2013.

[7] M. Jorgensen and K. Molokken-Ostvold," "How large are software cost overruns? A review of the 1994 CHAOS report," Information and Software Technology, vol. 48, no. 4, pp. 297-301, 2006.

[8] Standish Group International, "The chaos report," United States of America, 2015.

[9] A. Hussain and E. O. Mkpojiogu, "Requirements: Towards an understanding on why software projects fail," in AIP Conference Proceedings, 2016.

[10] S. Pedro and K. Jeffrey, "Does Agile work?-A quantitative analysis of agile project success," International Journal of Project Management, vol. 33, no. 5, pp. 1040-1051, 2015.

[11] VersionOne, CollabNet, " $13^{\text {th }}$ annual state of agile report," 2018.

[12] R. E. Levitt, "Towards project management 2.0," Engineering project organization journal, vol. 1, no. 3 , pp. 197-210, 2011.

[13] T. Chow and D.-B. Cao, "A survey study of critical success factors in agile software projects," The Journal of Systems and Software, vol. 81, no. 6, p. 961-971, 2008.

[14] D. Stankovic, V. Nikolic, M. Djordjevic and D.B. Cao, "A survey study of critical success factors in agile software projects in former Yugoslavia IT companies," The Journal of Systems and Software, vol. 86, no. 6, pp. 1663-1678, 2013.
[15] D. Hinde, "PRINCE2 Study Guide: 2017 Update," John Wiley \& Sons, 2018.

[16] Great Britain. Office of Government Commerce, Managing successful projects with PRINCE2, London: The Stationery Office, 2002.

[17] C. Bentley, Prince2: a practical handbook, Routledge, 2010.

[18] Agile Alliance, "Extreme Programing Glossary," 10 July 2020. [Online]. Available: https://www.agilealliance.org/glossary. [Accessed 10 July 2020].

[19] Don Wells, "When should Extreme Programming be Used," 1999. [Online]. Available: http://www. extremeprogramming.org/when.html. [Accessed 10 July 2020].

[20] W. W. Royce, "Managing the development of large software systems: concepts and techniques," in Proceedings of the 9th international conference on Software Engineering, 1987.

[21] "SDLC Waterfall Model" Tutorials Point," Tutorials Point, 2020. [Online]. [Accessed July 2020].

[22] K. Schwaber and J. Sutherland, "The scrum guidethe definitive guide to scrum: The rules of the game," SCRUM. org, Jul-2013, 2013.

[23] Scrum.org, "What is Scrum?," 2020. [Online]. Available: https://www.scrum.org/resources/what-isscrum. [Accessed July 2020].

[24] D. J. Anderson, Kanban: successful evolutionary change for your technology business, Blue Hole Press, 2010.

[25] M. Radovic-Markovic and B. Alecchi, Qualitative methods in economics, Taylor \& Francis, 2016.

[26] Digital.ai, "14 $4^{\text {th }}$ annual state of agile report," 2019. 